\title{
EXTENDING THE CONCEPT OF THE AUTOGRAFT FOR COMPLETE REPAIR OF TRANSPOSITION OF THE GREAT ARTERIES WITH VENTRICULAR SEPTAL DEFECT AND LEFT VENTRICULAR OUTFLOW TRACT OBSTRUCTION: A REPORT OF TEN CASES OF A MODIFIED PROCEDURE
}

\author{
Dominique Metras, MD \\ Bernard Kreitmann, MD \\ Alberto Riberi, MD \\ John-Godson Yao, MD \\ Elie El-Khoury, MD \\ François Wernert, MD \\ Adrienne Pannetier-Mille, MD
}

Background: In most cases of transposition of the great arteries with ventricular septal defect and left ventricular outflow tract obstruction, a Lecompte procedure (réparation à l'étage ventriculaire) is possible without interposition of a conduit between the right ventricle and pulmonary artery. However, the anterior location of the pulmonary arteries after the Lecompte maneuver may be a potential cause for right ventricular outflow obstruction, which continues to be reported in $5 \%$ to $25 \%$ of cases. We have used a tubular segment of aortic autograft to connect the pulmonary artery, left in the orthotopic posterior position (without the Lecompte maneuver), to the right ventricle in 10 consecutive patients with transposition, ventricular septal defect, and left ventricular outflow tract obstruction. Methods: Ten consecutive patients aged 2 months to 11 years (mean 32 months) have undergone a modified Lecompte operation. Eight had severe pulmonary stenosis, two had pulmonary atresia, and four had a restrictive ventricular septal defect at the time of the operation. Two had multiple ventricular septal defects. Seven had undergone one $(n=5)$ or two $(n=2)$ previous modified Blalock-Taussig shunts. All patients underwent a total correction with left ventricular-aortic intraventricular connection (four needed a ventricular septal defect enlargement), connection between the right ventricle and pulmonary arteries with a tubular segment of autograft aorta, without the Lecompte maneuver (anterior location of the bifurcation of the pulmonary arteries) on the right $(n=6)$ or the left $(n=4)$ of the aorta. No valvular device was used for the right ventricular outflow repair. Results: No early or late deaths occurred. One patient with multiple ventricular septal defects needed an early ( 2 weeks) reoperation for a residual muscular ventricular septal defect. All patients are currently in New York Heart Association class I, without medications, in sinus rhythm, at a mean follow-up of 30 months. Late results up to 3.6 years show no calcification on the chest roentgenogram, and at the most recent echocardiogram, right ventricular pressures were low (25 to $40 \mathrm{~mm} \mathrm{Hg}$, mean $33 \mathrm{~mm} \mathrm{Hg}$ ) and no significant gradient (over $10 \mathrm{~mm} \mathrm{Hg}$ ) was found between the right ventricle and pulmonary arteries. Left and right ventricular function was satisfactory. Conclusion: This modification of the Lecompte operation using a segment of autograft allows an excellent early and late result, with no danger of compression of anteriorly placed pulmonary arteries, no significant right ventricular outflow obstruction, and normal appearance of the tubular autograft. In view of laboratory and clinical evidence, normal growth of the autograft can be anticipated. It allows an elective correction
From the Service of Cardiothoracic Surgery, La Timone Children's Hospital, Marseilles, France.

Read at the Seventy-seventh Annual Meeting of The American Association for Thoracic Surgery, Washington, D.C., May 4-7, 1997.

Received for publication May 7, 1997; revisions requested June 9, 1997; revisions received July 9, 1997; accepted for publication July $17,1997$.
Address for reprints: Dominique Metras, MD, Unit of CardioThoracic Surgery, CHU Timone Enfants, Bd Jean Moulin, Cedex 5, 13885 Marseilles, France.

J Thorac Cardiovasc Surg 1997;114:746-54

Copyright (C) 1997 by Mosby-Year Book, Inc.

$0022-5223 / 97 \$ 5.00+0 \quad \mathbf{1 2 / 6 / 8 4 7 3 0}$ 
$T^{\mathrm{t}}$ he Rastelli procedure ${ }^{1}$ is considered to be standard in many centers for the repair of transposition of the great arteries (TGA) with ventricular septal defect (VSD) and left ventricular outflow tract obstruction (LVOTO). However, the need to interpose a valvular conduit between the right ventricle (RV) and the pulmonary artery (PA) has led to (1) the need for reoperations to change this conduit and (2) delay in achieving complete repair in infants because of the need to implant a large conduit.

With the intention of avoiding reoperations for future conduit replacement(s), Lecompte and associates ${ }^{2,3}$ have introduced a new operation and a very appealing concept, the REV (réparation à l'étage ventriculaire). The basic concepts are (1) resection of the outlet septum to construct a more direct connection between the VSD and aorta, (2) anterior location of the pulmonary tree after aortic transection, the Lecompte maneuver, ${ }^{4}$ and direct anastomosis between the PA and the right ventriculotomy.

The main immediate drawback of this operation is concern about anterior compression of the direct RV-PA connection because of its location in front of the anterior aorta. ${ }^{5}$ This was answered by a resection of a tubular portion of the aorta. ${ }^{6}$ Subsequently, there has been concern about secondary or late RV-PA obstruction leading to reoperation. This obstruction was reported in up to $26 \%{ }^{6}$ of patients and has led to reoperations.

We have modified the Lecompte operation by applying the autograft concept of a living tissue ${ }^{7}$ with capability of growth. ${ }^{8,9}$ Our modification consists of (1) resection of a tubular portion of the anterior aorta, (2) extension of the PA with this tubular aorta, and (3) direct anastomosis of this modified PA to the right ventriculotomy, without any tension; this leaves the pulmonary bifurcation orthotopically posteriorly located with no danger of compression and the possibility of growth and freedom from obstruction.

We report here on 10 consecutive patients operated on between the ages of 2 months and 11 years with a maximum follow-up of 46 months.

\section{Patients and methods}

Patients. From July 1993 to June 1996, 10 consecutive patients with TGA, VSD, and LVOTO underwent the modified Lecompte procedure with the use of autograft extension. The patients' ages at operation ranged from 2 months to 11 years (mean 32 months). All patients were younger than 3 years of age except one, and three were younger than 1 year of age.

Eight patients had undergone a Rashkind atrioseptostomy at the initial evaluation. Two patients had multiple VSDs, and four had a restrictive VSD, one of which had almost closed during the follow-up after a previous modified Blalock-Taussig shunt.

One of the patients with multiple VSDs had abnormal papillary muscle attachment of the mitral valve on the inferior margin of the perimembranous VSD and abnormal tricuspid attachments upward on the conal septum.

Eight patients were considered to have d-TGA with an anteroposterior position of the great arteries, the aorta being slightly to the right. Two were considered to have 1-TGA, the aorta being considered more on the left side. Eight patients had a severely stenotic bicuspid pulmonary valve with a narrow initial portion of the main $\mathrm{PA}$ and frequent additional subpulmonary stenosis. In two patients the pulmonary orifice was atretic.

Seven had earlier undergone a palliative modified Blalock-Taussig shunt and two of them had undergone two modified Blalock-Taussig shunts.

Surgical technique. All patients were operated on via a median sternotomy. Except for one patient, for whom cardiopulmonary bypass (CPB) was conducted at normothermia, all patients had hypothermic CPB $\left(25^{\circ} \mathrm{C}\right)$. One patient was subjected to a period of deep hypothermic circulatory arrest (the 2-month-old baby). Before CPB, the ascending aorta and the PAs were dissected free, beyond the pericardial reflection, and the previous modified Blalock-Taussig shunts were controlled. They were taken down by division and suture or clip ligation in three patients with dense fibrosis reaction before the institution of CPB. CPB was instituted between an aortic cannula (placed as distally as possible) and two caval cannulas. After aortic crossclamping and cardioplegia, the intracardiac anatomy was inspected and deemed adequate for repair through a right atrial incision.

The PA was transected above the level of the commissures, an area generally narrow. After the PA had been transected, it was decided whether the connection to the $\mathrm{RV}$ was to be done on the right or the left of the aorta. The incision in the RV was then done obliquely under the aortic anulus. Its location was decided according to two factors (1) avoidance of coronary vessels and (2) decision to connect the PA to the right or the left of the aorta. The side of the RV-PA connection was decided on the basis of anatomic features allowing the most direct connection 

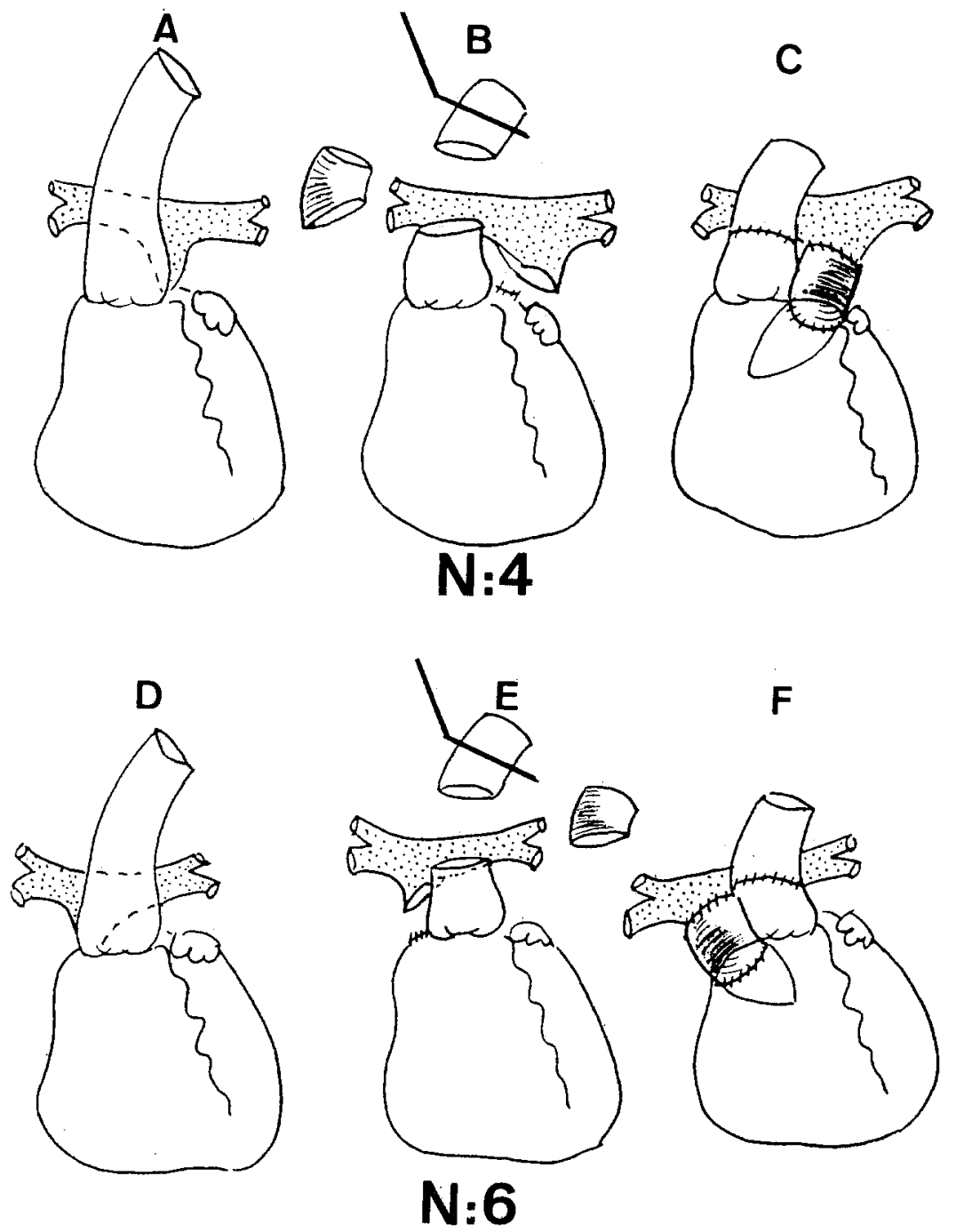

Fig. 1. Operative technique: A, Appearance of the transposed aorta with PA located toward the left. B, Resection of a tubular segment of ascending aorta division, suture of proximal end of PA, and opening of main PA. C, Autograft reconstruction on the left side of the aorta (four patients). D, Aspect of the transposed aorta with the PA located to the right. E, Same as part B. F, Autograft reconstruction on the right side of the aorta (six patients).

and the least likely to be subject to compression. Then a transverse aortotomy was done above the commissures and a tubular segment of the aorta was resected and stored in blood (Fig. $1 ; B$ and $E$ ). Because of the concave structure of the ascending aorta, this segment was necessarily asymmetric, with the widest portion being between 16 and $20 \mathrm{~mm}$ and the narrowest portion being around 5 to $6 \mathrm{~mm}$ when they were measured.

After exposure of the VSD, the aortic valve, and the conal septum, the conal septum was resected if it was hypertrophic and obstructive according to Lecompte. ${ }^{2}$ That was necessary in six patients. In one patient, with abnormal tricuspid attachment on the conal septum, a piece of conal septum that supported the chordae was detached, and this muscular base was reinserted to the patch after construction of the VSD-aorta channel. In four patients this conal septum was not prominent. The resection was helped, as described, ${ }^{2,3}$ by a Hegar bougie inserted in the left ventricle (LV) through the pulmonary valve. It was also helped by the ability to view the area through the transaortic valve. This maneuver was also used to enlarge the VSD in four patients. The enlargement included resection of fibrous septal tissue, resection of subpulmonary fibrotic tissue, and resection of conal septum. This enlargement was directed upward and anteriorly.

The tunnel between the VSD and aorta was then constructed with an oval Dacron patch sutured with 

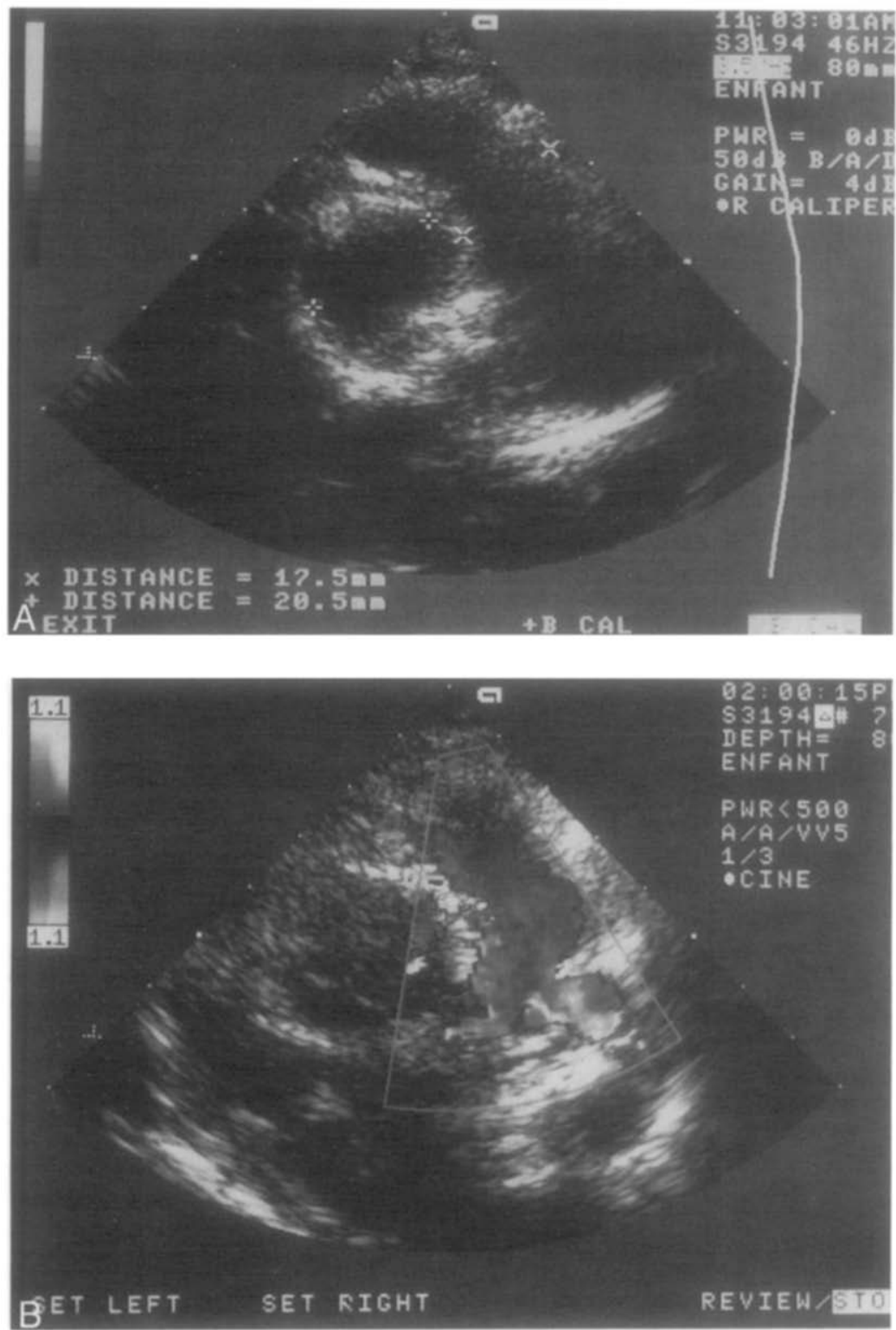

Fig. 2. One year postoperative echocardiographic (A) and Doppler appearance (B) of the RV outflow tract. The outflow (left-sided) is wide $(17 \mathrm{~mm})$, without turbulence, the PA bifurcation is seen orthotopically posterior to the aorta.

interrupted pledget-supported sutures. The upper part was occasionally run. The area was viewed through the aortic valve to ensure freedom from LVOTO.

In one patient with multiple VSDs and abnormal attachment of the mitral valve to the margin of the VSD, it was possible to ensure that the repair did not interfere with valvular function by viewing the area through the aorta. In this patient, the abnormal tricuspid attachment was anchored to the VSD patch. Next, the aorta was reconstructed by an end-to-end anastomosis with a 6-0 monofilament suture, without any tension, because the long ascending aorta had been dissected free, and the two ends were easily attached.
The atrial septal defect was closed with interrupted sutures, the right atriotomy was closed, and finally the RV-PA junction was reconstructed. In six patients, the RV-PA junction was located on the right side of the aorta (Fig. 1,C) and in four patients it was located on the left side (Fig. 1, F). The tubular segment of aorta was anastomosed with a 7-0 absorbable suture to the obliquely incised main PA. The posterior rim of the reconstructed PA was anastomosed to the upper part of the ventriculotomy (Fig. 1, $C$ and $F$ ) with a 6-0 running absorbable suture, and a gusset of autologous pericardium closed the anterior aspect, the conduit being left valveless. Most of this final repair was done with a beating heart after the aortic crossclamp had been released. 

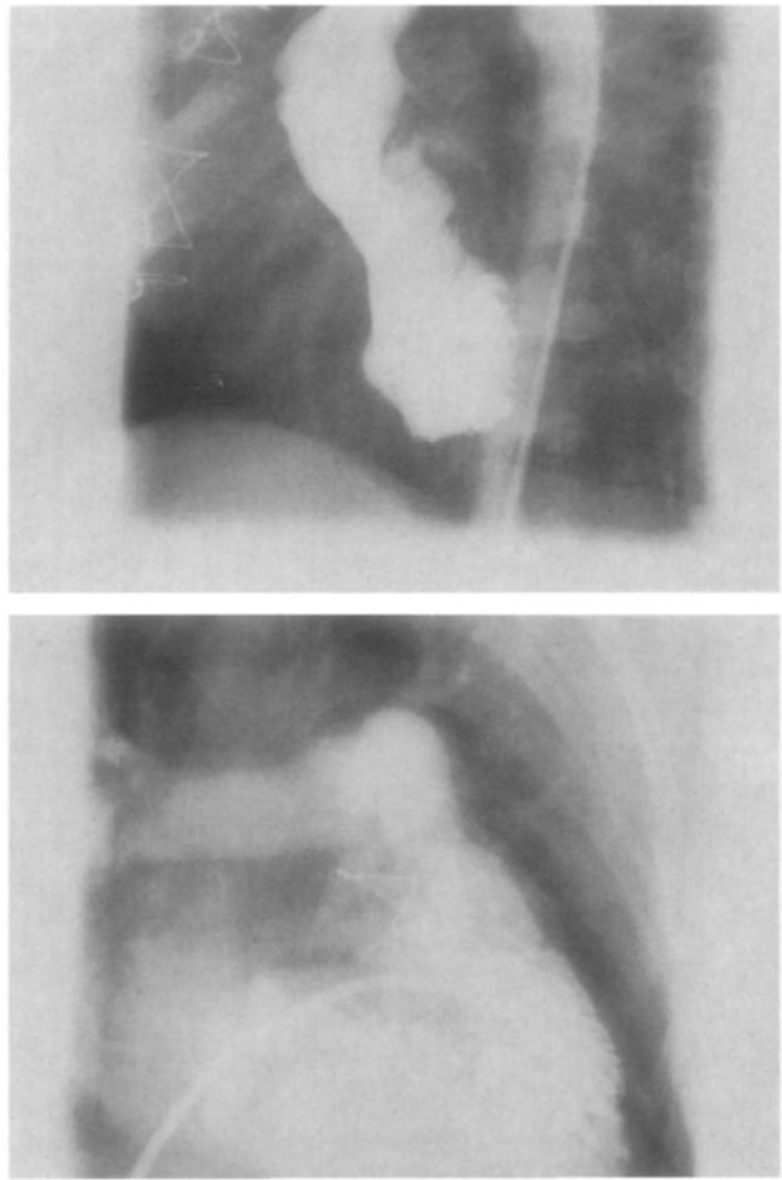

Fig. 3. Postoperative angiograms (1 year after the operation) in a 4-year-old patient. The RV-PA reconstruction was located on the left of the aorta (bottom). The LV: aorta connection is wide open in this case where there was an extensive VSD enlargement.

\section{Results}

The surgical procedure included an aortic crossclamp time of between 90 and 140 minutes (mean 113 minutes). The shortest crossclamp times were obtained with experience, in the last five patients. Intraoperative bleeding and transfusions (mean 120 $\mathrm{ml}$ per patient) were reduced, and no postoperative deaths occurred. The postoperative course was often not easy, with an intensive care unit stay of a mean of 12 days.

Two patients had a long and complicated postoperative course (28 and 30 days). One, who had respiratory distress, needed prolonged ventilation and the other, who had a residual VSD shunt, needed a reoperation after 2 weeks. The other eight patients stayed from 3 to 10 days in the intensive care unit.

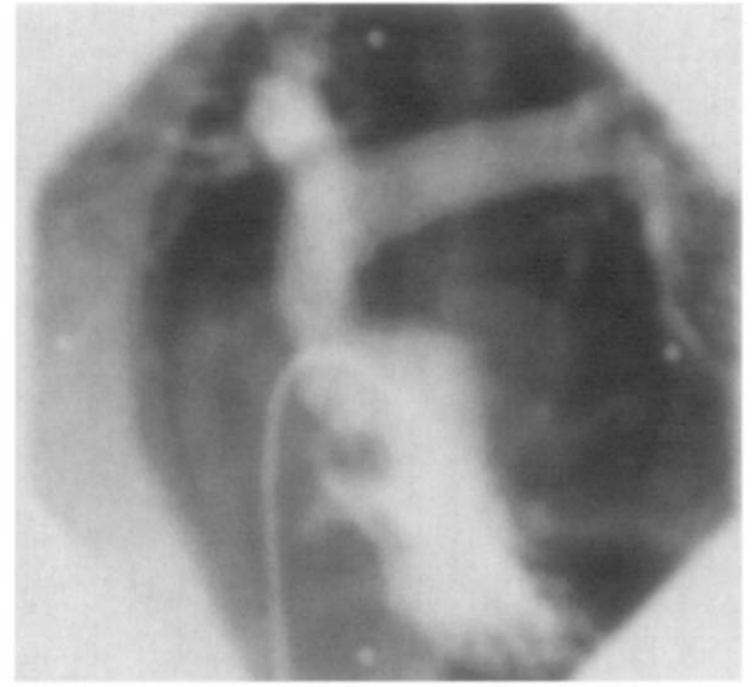

Fig. 4. Postoperative angiogram in the RV (systole): Smooth RV-PA right-sided connection 1 year after the operation. This patient had multiple VSDs and reimplantation of a detached tricuspid conal papillary muscle. Angiographically, the tricuspid valve is competent.

All patients were eventually discharged after a mean hospital stay of 18 days (11 to 45 days). They were subjected to regular follow-up. One patient has a moderate residual VSD that progressively decreased and is now insignificant 3 years after the procedure.

The follow-up period is from 11 to 43 months (mean 30 months). All patients are in New York Heart Association class I, without cardiac medications, and all are in sinus rhythm.

The immediate $\mathrm{RV} / \mathrm{LV}$ pressure ratio at the completion of bypass ranged from $20 \%$ to $50 \%$ and the highest ratios decreased with time, with the progressive decrease in RV hypertrophy.

At the last echocardiographic and Doppler evaluation the RV outflow tract was free in all patients (Fig. 2) and the RV pressures evaluated by Doppler echocardiography ranged from 25 to $40 \mathrm{~mm} \mathrm{Hg}$, mean $33 \mathrm{~mm} \mathrm{Hg}$. No significant RV-PA gradient over $10 \mathrm{~mm} \mathrm{Hg}$ was found. The LV-aorta pathway was free of obstruction, including in the four patients in whom the VSD needed to be enlarged (Fig. 3 , top). Ventricular function was normal in all patients.

Of special interest is the result in the patient operated on at the age of 2 months, with a weight of $4.5 \mathrm{~kg}$. He is now 3.5 years old and, having grown, has demonstrated an excellent result. 

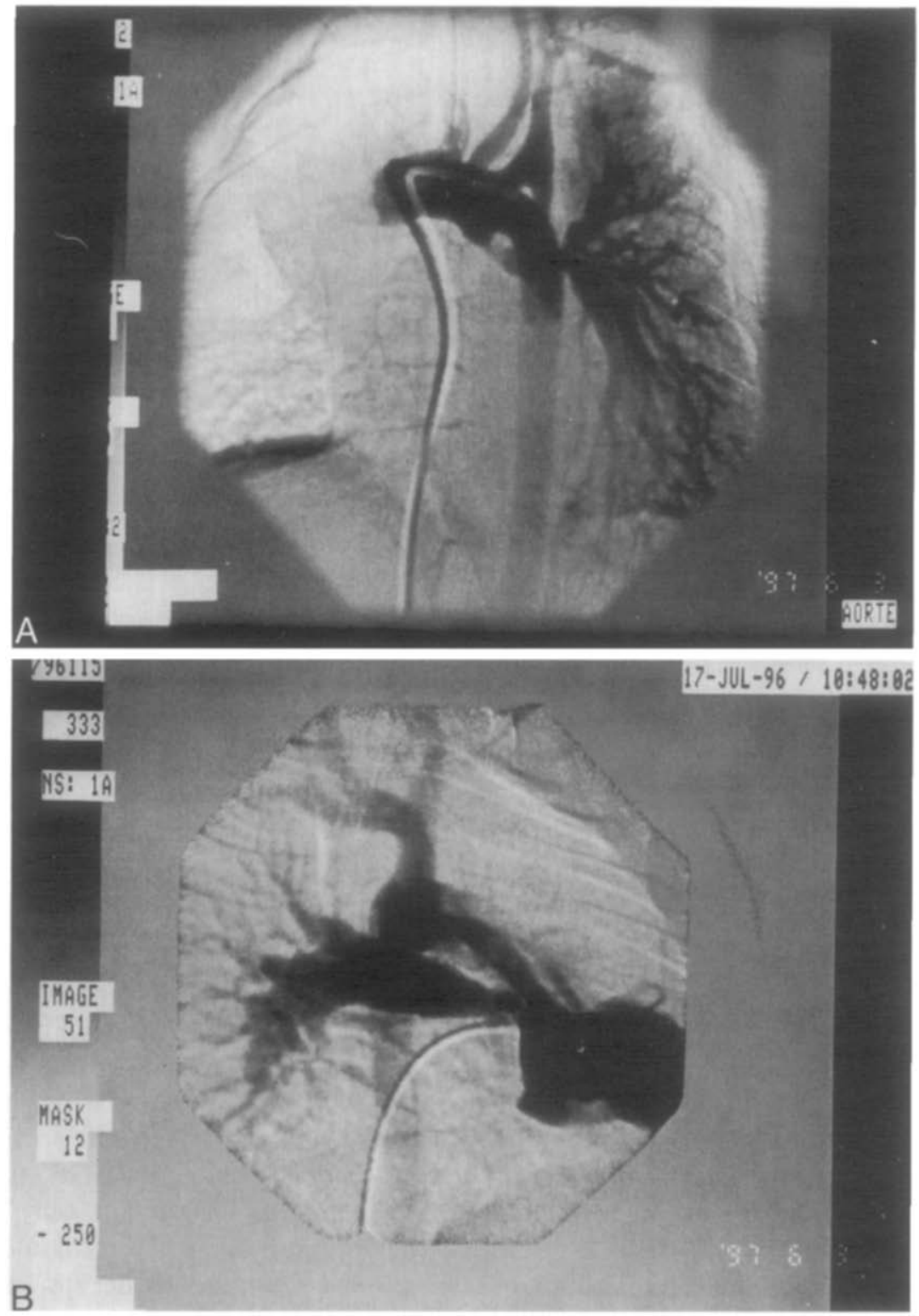

Fig. 5. A, Angiogram in the horizontal aorta: A small left PA originates from a ductuslike structure. The modified Blalock-Taussig shunt is visualized. B, The main PA with valvular and supravalvular stenosis gives rise to the right $\mathrm{PA}$.

In all patients, the chest roentgenogram did not show any calcification of the tubular aortic autograft.

Two patients have been recatheterized and the angiograms show a satisfactory RV-PA repair either on the right (Fig. 4) or on the left of the aorta (Fig. 3 , bottom).

Incidentally, the patient depicted in Fig. 4 is the patient with multiple VSDs and abnormal attachments of tricuspid and mitral chordae who under- went tricuspid papillary muscle reinsertion. He has no tricuspid insufficiency.

\section{Discussion}

The Rastelli operation, ${ }^{1}$ described in 1969 , has long been considered the procedure of choice in the repair of TGA, VSD, and LVOTO. The only major drawback of this operation is the frequent $(67 \%)$ late occurrence of RV-PA obstruction, ${ }^{6}$ leading to mandatory change of the valve conduit, although the 


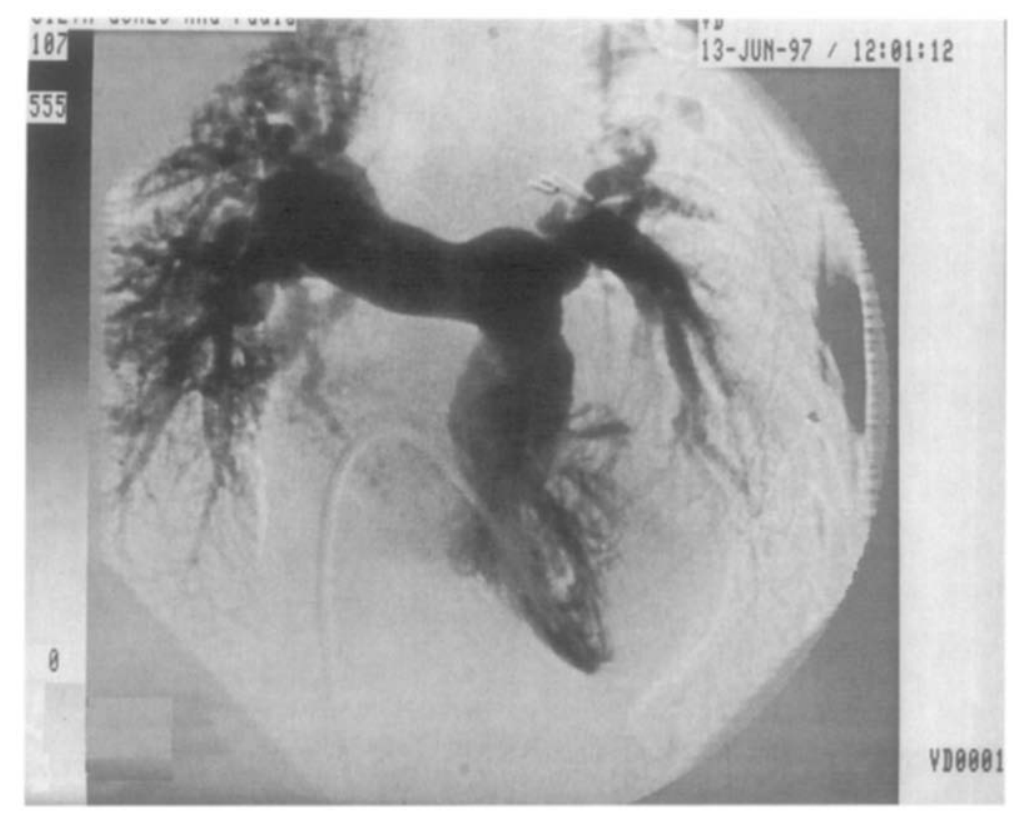

Fig. 6. Postoperative RV angiogram. A satisfactory pulmonary neobifurcation has been constructed between the main PA and left PA and connected to the RV with the aortic autograft.

simple patch repair after the conduit replacement ${ }^{10}$ without interposing a new conduit may lead to only one reoperation. It must also be stated that the use of the cryopreserved pulmonary homograft has shown a considerable improvement in conduit longevity over the aortic homograft in several reports and, in particular, in the same institution. ${ }^{11}$

However, the need to interpose a conduit has also led to complete correction at an age when a larger conduit could be placed, therefore leading to several previous palliative procedures.

The REV-Lecompte operation was essentially designed to avoid reoperations for conduit obstruction. However, despite excellent results, $3,12,13$ RV-PA obstruction has been reported to occur in $26 \%$ of patients, ${ }^{6,14}$ leading to reoperations in $5 \%$ to $15 \%$. The anteriorly located pulmonary bifurcation, in front of the transposed aorta, is possibly the cause for this obstruction ${ }^{5}$ and has led the authors to resect a cylinder of aorta to decrease this tension. ${ }^{6}$ Still, the aorta stays anteriorly transposed and may be a risk factor for PA stenosis. More recently, some patients have needed a reoperation in adolescence (Sidi D: personal communication, 1997).

In our patients, our decision on where to place the autograft was essentially based on the likelihood of avoiding anterior compression, in particular, avoiding crossing the midline. No patient needed a de- layed sternal closure, even after a long CPB time and an increased risk of compression of the heart.

Some authors ${ }^{14,15}$ have reported direct anastomosis between the RV and PA after transection of this main PA and dissection of the branches in 19 patients, with one reoperation for RV-PA obstruction. We think, however, that this procedure must necessarily lead to tension on the anastomosis. In our patients, the pulmonary branches were also dissected free distally and only the extension with the autograft allowed a tension-free anastomosis.

Aortic autograft tissue has been reported to be used as a small constructed tube to palliate one case of VSD and pulmonary atresia with hypoplastic PAs, connecting the RV and the PAs ${ }^{2}$; however, so far as we know, a complete tubular autograft has not been reported to extend the PA tree.

We see many advantages in the modified REVLecompte procedure with a tubular segment of autograft.

1. It avoids any tension on the RV-PA anastomosis.

2. Leaving the PAs orthotopically posterior, it avoids anterior compression of these PAs.

3. It can be used as a primary corrective operation, even in young babies, without palliative surgery.

4. The autograft is living tissue, which has been shown to have the capacity for growth in both 
clinical $^{9}$ and experimental studies. ${ }^{8}$ The absence of midterm calcification or stenosis is presumably the indirect signs of growth in our patients.

5. Reoperation for RV-PA stenosis is unlikely to be necessary.

Although the short-term and midterm results are excellent, long-term results are needed to confirm all these statements. In addition, this procedure is not mandatory in all patients because, on the basis of the size and location of the PAs, some patients can have a direct connection without the Lecompte maneuver (12\% in Lecompte's experience $\left.{ }^{13}\right)$ and in others the Lecompte maneuver is perfectly sound, in particular in patients with a small aorta. Finally, as in all these procedures, the valveless RV-PA connection is still present, with its own set of prospective problems. As in all valveless RV-PA connections (tetralogy of Fallot with transannular patch, ${ }^{16}$ removal of valvulated conduit, and substitution with a simple patch ${ }^{10}$ ), there is a possible need for a late reoperation. However, this disadvantage is outweighed, we think, by the very likely absence of reoperation for conduit obstruction.

\section{Addendum}

Since this paper was written two more patients have been operated on. One deserves special mention. The patient had TGA, VSD, and severe pulmonary stenosis. The hypoplastic left PA was originating from a ductuslike structure (Fig. 5, $A$ )and was separated from the right PA, which originated from a hypoplastic main PA (Fig. 5, B).

This baby had a modified Blalock-Taussig anastomosis with a $5 \mathrm{~mm}$ polytetrafluoroethylene graft on the left side at the age of 5 months. At 15 months he underwent a total correction with reconstruction of a pulmonary bifurcation anastomosing the detached main PA and the left PA. This neobifurcation was opened longitudinally and connected to the RV with a segment of autograft aorta. A postoperative RV angiogram showed an excellent result (Fig. 6).

This case shows that our concept can be extended to more complex PA anatomic conditions, even with nonconfluent PAs.

\section{REFERENCES}

1. Rastelli GC, McGoon DC, Wallace RB. Anatomic correction of transposition of the great arteries with ventricular septal defect and subpulmonary stenosis. J Thorac Cardiovasc Surg 1969;58:545-52.

2. Lecompte Y, Neveux JY, Leca F, et al. Reconstruction of the pulmonary outflow tract without prosthetic conduit. J Thorac Cardiovasc Surg 1982;84:727-33.

3. Lecompte Y. Réparation à l'étage ventriculaire-The REV procedure: technique and clinical results. Cardiol Young 1991;1:63-70.

4. Lecompte Y, Zannini L, Hazan E, et al. Anatomic correction of transposition of the great arteries: new technique without use of a prosthetic conduit. J Thorac Cardiovasc Surg 1981; 82:629-31.

5. Litwin SB. Discussion of Vouhé et al. ${ }^{6}$

6. Vouhé PR, Tamisier D, Leca F, Ouaknine R, Vernant F, Neveux JY. Transposition of the great arteries, ventricular septal defect, and pulmonary outflow tract obstruction: Rastelli or Lecompte procedure? J Thorac Cardiovasc Surg 1992;103:428-36.

7. Ross DN. Editorial: Reflections on the pulmonary autograft. J Heart Valve Dis 1993;2:363-64.

8. Kreitmann B, Riberi A, Jimeno MT, Metras D. Experimental basis for autograft growth and viability. J Heart Valve Dis 1995;4:379-83.

9. Elkins RC, Knott-Craig CJ, Ward KE, McCue C, Lane MM. Pulmonary autograft in children: realized growth potential. Ann Thorac Surg 1994;57:1387-94.

10. Danielson GK, Downing TP, Schaff HV, Puga FJ, Di Donato RM, Ritter DG. Replacement of obstructed extracardiac conduits with autogenous tissue reconstruction. J Thorac Cardiovase Surg 1987;93:555-9.

11. Bando KO, Danielson GK, Schaff HV, Mair DD, Julsrud PR, Puga FJ. Outcome of pulmonary and aortic homografts for right ventricular outflow tract reconstruction. J Thorac Cardiovase Surg 1995;109:509-18.

12. Rubay J, Lecompte Y, Batisse A, Durandy Y, Dibie A, Lemoine $\mathrm{H}$, et al. Anatomic repair of anomalies of ventriculo-arterial connection (REV): results of a new technique in cases associated with pulmonary outflow tract obstruction. Eur J Cardiothorac Surg 1988;2:305-11.

13. Borromée L, Lecompte Y, Batisse A, Lemoine G, Vouhé P, Sakata $R$, et al. Anatomic repair of anomalies of ventriculoarterial connection associated with ventricular septal defect. II. Clinical results in 50 patients with pulmonary outflow tract obstruction. J Thorac Cardiovasc Surg 1988;95:96-102.

14. Kim YJ, Song H, Lee JR, Rho JR, Suh KP. Lecompte procedure for complete transposition of the great arteries with ventricular septal defect and pulmonary stenosis. Ann Thorac Surg 1994;57:876-9.

15. Van Son JAM, Sim EKW. Lecompte operation with preservation of the pulmonary valve for anomalies of ventriculoarterial connection with ventricular septal defect and subpulmonary stenosis. Eur J Cardiothorac Surg 1996;10:585-89.

16. Kirklin JK, Kirklin JW, Blackstone EH, Milano A, Pacifico AD. Effect of transannular patching on outcome after repair of tetralogy of Fallot. Ann Thorac Surg 1989;48:783.

\section{Discussion}

Mr. Donald N. Ross (London, England). I want to congratulate Dr. Metras for an ingenious operation and innovative approach to the autograft technique. In view of the known growth potential of autogenous living tissue, do you visualize further applications of the autograft principle in congenital cyanotic heart disease and hypoplastic tissue? I hope so.

Dr. Metras. Thank you, Mr. Ross. This is a mirror application of the beautiful concept of total autograft that you introduced to cardiac surgeons.

Dr. Jan M. Quaegebeur (New York, N.Y.). I believe this technique is very useful. We, too, have been interested in performing the REV operation instead of doing a Rastelli operation. I would like to mention one patient whom we believed to be an ideal candidate for this operation. This 
patient had systemic pressures in the RV after the repair. The gradient was in the hilum on both sides because of excess traction on the bifurcation of the PA, so we had to undo the repair. I believe your technique would obviously relieve that problem.

Dr. Metras. Thank you, Dr. Quaegebeur, for these comments. Like you, I think that a tension-free anastomosis is essential if an unobstructed RV-PA connection and no future gradient are to be obtained. I must add that resecting part of the ascending aorta when during end-toend anastomosis of the ascending aorta lifts the heart a little bit so that tension on the RV-PA anastomosis is decreased, and leaving the PAs posterior to the aorta avoids the problem you have mentioned.
Dr. Zohair Yousef Al-Halees (Riyadh, Saudi Arabia). We have used the same concept of using autologous tissue in reconstructions for congenital heart disease. We used a cylinder of the PA to construct the aorta in supravalvular aortic stenosis. After about 6 years' follow-up, the result is gratifying, with evidence of growth and no calcification.

We also have used a cylinder of the aorta that is opened as a patch for reconstruction of difficult narrowed PAs. After about 5 years of follow-up on those patients, we have observed evidence of growth and no calcification.

Dr. Metras. Thank you very much. I believe you have answered Mr. Ross's questions about other applications of the autograft concept and tissue.

\section{Availability of Journal back issues}

As a service to our subscribers, copies of back issues of The Journal of Thoracic and Cardiovascular Surgery for the preceding 5 years are maintained and are available for purchase from Mosby at a cost of $\$ 15.00$ per issue until inventory is depleted. The following quantity discounts are available: $25 \%$ off on quantities of 12 to 23 , and one third off on quantities of 24 or more. Please write to Mosby-Year Book, Inc., Subscription Services, 11830 Westline Industrial Drive, St. Louis Mo 63146-3318, or call 800-453-4351 or 314-453-4351 for information on availability of particular issues. If unavailable from the publisher, photocopies of complete issues may be purchased from UMI, 300 N. Zeeb Rd., Ann Arbor, MI 48106, 313-761-4700. 